\title{
CARGAS DE TRABALHO E CONDIÇÕES DE TRABALHO DA ENFERMAGEM : revisão integrativa
}

\author{
Roseli SCHM OE LLERa, Letícia de Lima TRINDADE ${ }^{\mathrm{b}}$, M árcia Binder NEISc, \\ Francine Lima GELBCKE ${ }^{d}$, D enise Elvira Pires de PIRE Se
}

\section{RESUM 0}

0 presente estudo teve por objetivo conhecer a produção teórica sobre cargas de trabal ho e condições de trabal ho dos profissionais de enfer magem. Para tanto, foi real izada uma revisão integ rativa que incluiu artigos científicos, teses e disser tações, indexados nas bases da Biblioteca V irtual de Saúde e Banco D igital de T eses nos últimos dez anos. E ntre os 132 trabal hos identificados, foram selecionadas 27 produções. Os resultados indicaram as cargas de trabal ho como responsáveis pelo desgaste dos profissionais, influenciando a ocorrência de acidentes e os problemas de saúde. Para amenizar tais cargas de trabalho, os estudos apontam algumas estratégias, como adequação do quantitativo de pessoal, educação continuada e melhores condições de trabal ho. T em-se como desafio a realização de pesquisas que revelem com mais precisão a relação entre as cargas e as condições de trabal ho da equipe de enfermagem, haja vista o quanto comprometem a saúde dos trabal hadores.

D escritores: Carga de trabal ho. Condições de trabal ho. Saúde do trabal hador. E nfer magem do trabal ho.

\section{RESUMEN}

E studio que objetivó conocer la producción teórica sobre las cargas de trabajo y condiciones de trabajo de profesionales de enfermería. Para eso, se realizó una revisión integradora que incluyó artículos científicos, tesis o disertaciones, indexados en bases de B iblioteca Virtual de Salud y B anco D igital de Tesis en los últimos diez años. E ntre los 132 trabajos identificados, fueron seleccionadas 27 producciones. $L$ os resultados indicaron las cargas de trabajo como responsables por el desgaste de los profesionales, influenciando la ocur rencia de accidentes y problemas de salud. Para amenizar esas cargas de trabajo los estudios apuntan algunas estrategias: adecuación del cuantitativo de personal, educación continuada y mejores condiciones de trabajo. Se tiene el desafío de la realización de pesquisas que revelen con mayor precisión la relación entre las cargas de trabajo y las condiciones de trabajo de la equipe de enfer mería, consider ándose cuanto estas comprometen la salud de los trabajadores.

Descriptores: Carga de trabajo. Condiciones de trabajo. Salud laboral. E nfermería del trabajo.

T ítulo: Carga de trabajo y condiciones de trabajo de la enfermería: revisión integradora.

\section{ABST RACT}

This study reviews theoretical production concerning workloads and working conditions for nurses. For that, an integrative review was carried out using scientific articles, theses and dissertations indexed in two Brazilian databases, Virtual $\mathrm{H}$ ealth Care L ibrary (Biblioteca Virtual de Saúde) and D igital D atabase of D issertations (Banco Digital de Teses), over the last ten years. F rom 132 identified studies, 27 were selected. R esults indicate workloads as responsible for professi onal weariness, affecting the occur rence of work accidents and health problems. In order to adequate workloads studies indicate some strategies, such as having an adequate numbers of employees, continuing education, and better working conditions. The challenge is to continue research that reveal more precisely the relationships betw en w orkloads, working conditions, and health of the nursing team.

D escriptors: W orkloads. Working conditions. 0 ccupational health. 0 ccupational health nursing. T itle: $\mathrm{N}$ ursing w orkloads and working conditions: integrative review.

\footnotetext{
a M estre em E nfermagem, E nfermeira do Hospital U niversitário (HU) da U niversidade Federal de Santa Catarina (U F SC), F Iorianópolis, Santa Catarina, Brasil.

${ }^{b}$ M estre em E nfermagem, D outoranda pelo Programa de Pós-G raduação em E nfermagem da U F SC, Florianópolis, Santa Catarina, Brasil.

c M estranda pelo Programa de Pós-G raduação em E nfermagem da U F SC, E nfermeira do HU -U F SC, F Iorianópolis, Santa Catarina, Brasil.

d D outora em Enfermagem, Professora A ssociada da U F SC, Diretora de E nfermagem do HU -U F SC, F Iorianópolis, Santa Catarina, Brasil.

e Pós-D outora em Ciências Sociais, Professora A ssociada da U F SC, F lorianópolis, Santa Catarina, Brasil.
} 


\section{INT RODUÇÃO}

0 trabalho em saúde é fundamental para a vida humana. Entende-se trabal ho como uma ação transformadora, e na área da saúde especifica-se pela identidade de natureza entre os sujeitos que recebem a assistência e os cuidadores, além da indissociabilidade entre o processo de produção e 0 produto do trabalho(1).

0 processo de trabalho de enfermagem é parte do processo de trabalho em saúde e requer estudos, ações e formulação de estratégias com vistas à real ização de cuidados seguros e à val orização profissional ${ }^{(2)}$.

As condições de trabalho da equipe de enfermagem, principalmente nos hospitais, têm sido consideradas impróprias no que concerne às especificidades do ambiente gerador de riscos à saúde. A remuneração inadequada, a acumulação de escalas de serviço, 0 aumento da jornada de trabalho, as características tensiógenas dos serviços de saúde (tanto pela natureza do cuidado prestado às pessoas em situações de risco quanto pela divisão social do trabalho), a hierarquia presente na equipe de saúde e o desprestígio social, entre outros fatores, associam-se às condições de trabalho da equipe de enfermagem e refletem-se na qualidade da assistência prestada ao usuário e no sofrimento psíquico dos profissionais. Esse conjunto de problemas tem levado diversos profissionais ao abandono da profissão, tendo como consequência a diminuição do quantitativo de profissionais no mercado de trabalho(3).

O Núcleo de Estudos sobre Trabalho, Cidadania, Saúde e E nfermagem (PRÁXIS) da U niversidade Federal de Santa Catarina (UFSC) tem o trabal ho como categoria central de análise. $0 \mathrm{G}$ rupo foi criado visando desenvolver estudos sobre métodos assistenciais e preocupações sobre o trabalho da enfermagem, resgatando a subjetividade e dedicando-se à análise dos sujeitos envolvidos no processo de cuidado em saúde e enfer magem ${ }^{(4)}$. $\mathrm{N}$ esse contexto, é de interesse dos pesquisadores do PRÁXIS conhecer o processo de trabal ho e os elementos que interagem na relação trabal hador e objeto, assim como as formas de organização do trabalho, em especial nos aspectos que geram processos de desgaste.

A ideia de carga de trabal ho tem sido utilizada na literatura para estudar a saúde dos trabal hadores. Esta é definida como um dos elementos do processo de trabal ho que interagem entre si e com o corpo do trabalhador, desencadeando alterações nos processos biopsíquicos, que se manifestam como desgaste físico e psíquico, potenciais ou efetivamente apresentados ${ }^{(5)}$.

N esse sentido, questiona-se: 0 que traz a literatura atual sobre a relação entre as condições e as cargas de trabalho dos profissionais de enfermagem? Quais são as principais conclusões dos estudos sobre a temática?

D essa forma, o presente estudo objetivou conhecer a produção teórica acerca das condições e cargas de trabalho dos profissionais de enfermagem, avaliando os resultados desses estudos como forma de identificar até que ponto esses fatores têm gerado desgaste aos trabal hadores.

\section{METODOLOGIA}

Para a realização desse estudo utilizou-se a revisão integrativa, que se caracteriza por resgatar e sumarizar pesquisas anteriores, per mitindo conclusões que articulam os resultados obtidos em diferentes estudos ${ }^{(6)}$.

A revisão seguiu as seguintes etapas: sel eção do tema e das palavras-chave; definição das bases de dados para busca; estabelecimento dos critérios para sel eção da amostra; identificação do panorama geral do resultado da busca; adaptação do formulário para registro dos dados; análise; interpretação dos resultados.

O levantamento bibliográfico foi realizado por meio de consulta ao portal da Biblioteca Virtual de Saúde (BVS) incluindo as fontes de informações: Literatura $L$ atino-A mericana e do Caribe em Ciências da Saúde (LILACS), M edical L iterature A nalysis and Retrieval System Online (MEDLINE), Scientific Electronic Library Online (SciE LO), Biblioteca Cochrane, e consulta ao Banco Digital de Teses (BDT D) da Coordenação de A perfeiçoamento de Pessoal de N ível Superior (CAPES), limitando-se às publicações dos últimos dez anos (janeiro de 2000 a agosto de 2010). A busca do material ocorreu entre os meses de março e agosto de 2010, considerando as expressões: "condições de trabal ho e cargas de trabalho em enfermagem" e "condições de trabal ho e carga de trabal ho em enfermagem". Para constituir a amostra foram selecionados os trabaIhos que atenderam aos seguintes critérios: textos na forma de artigos, teses ou dissertações disponíveis online na íntegra, que abordassem a temática 
nos idiomas português, inglês ou espanhol, publicados nos últimos dez anos.

Considerando-se as bases de dados, foram identificadas 132 publicações. Na BVS, utilizando busca integrada, todos os índices e todas as fontes, apareceram 92 artigos, sendo 70 relacionados a carga de trabalho e 22 a cargas de trabalho. NaBDT D apareceram 40 artigos, 20 com a terminologia carga de trabal ho e 20 com cargas de trabal ho.

A pós a leitura dos títulos e resumos, foi excluída toda publicação duplicada e as não correspondente aos critérios de inclusão. Selecionou-se 27 estudos, que foram sistematizados por meio de formulário de análise individual, que continha os seguintes itens: referências (autor, periódico, ano), tipo de artigo (pesquisa, revisão de literatura ou outros), objetivo central do artigo, metodologia (tipo de estudo, sujeitos, instrumentos de col eta de dados) e resultados dos estudos. E m seguida, rea- lizou-se a leitura dos trabal hos sel ecionados na íntegra, sendo as informações sistematizadas e categorizadas, visando atender o objetivo da proposta.

Ressalta-se que foram respeitadas integralmente as idéias dos autores, conforme preconiza a lei dos dir eitos autorais, sendo identificados os trechos aliterais e literais e seus respectivos autores.

\section{RESULTADOS E DISCUSSÕES}

0 protocolo de pesquisa aplicado aos 27 estudos selecionados permitiu identificar que 12 $(44,4 \%)$ são artigos em periódicos e 15 (55,5\%) são produções de programas de Pós-G raduação, entre dissertações (dez) e teses (cinco). As produções integrantes deste estudo estão expostas na tabela abaixo, na qual são identificados 0 ano de produção, autor(es), título do trabalho e o local de publicação (Q uadro 1).

\begin{tabular}{|c|c|c|c|}
\hline T ítulo & Autores & Ano & O rigem $\mathrm{P}$ ublicação \\
\hline $\begin{array}{l}\text { Instrumento de classificação de pacientes de } \\
\text { Perroca: validação clínica }{ }^{(7)}\end{array}$ & Perroca M G & 2000 & $\begin{array}{l}\text { U niver sidade de São Paulo } \\
\text { [ tese] }\end{array}$ \\
\hline $\begin{array}{l}\text { Estudo do processo de trabal ho da enfermagem } \\
\text { em hemodinâmica: desgastes, cargas de trabal ho } \\
\text { e fatores de riscos à saúde do trabal hador }{ }^{(8)}\end{array}$ & Santos PR & 2001 & $\begin{array}{l}\text { E scola N acional de } \\
\text { Saúde Pública } \\
\text { [ dissertação] }\end{array}$ \\
\hline $\begin{array}{l}\text { Formação do E nfermeiro para detecção precoce } \\
\text { de desvios psicomotores em lactentes - Fortale- } \\
\text { za, Estado do Ceará, Brasi|(19) }\end{array}$ & $\begin{array}{c}\text { Nóbrega M, } \\
\text { Jorge M, } \\
\text { Valdés M, } \\
\text { Silva L }\end{array}$ & 2003 & Acta Sci H ealth Sci. \\
\hline $\begin{array}{l}\text { A nálise da validade de constructo do instrumen- } \\
\text { to de classificação de pacientes proposto por } \\
\text { Perroca(10) }\end{array}$ & $\begin{array}{l}\text { Perroca M G, } \\
\text { Gaidzinski R }\end{array}$ & 2004 & $\begin{array}{l}\text { Rev Latino-Am } \\
\text { Enfermagem }\end{array}$ \\
\hline $\begin{array}{l}\text { Condições de trabal ho de auxiliares de enferma- } \\
\text { gem de um instituto de ortopedia e traumatologia } \\
\text { de um hospital público de São Paul o(11) }\end{array}$ & $\begin{array}{l}\text { Gonçalves } \\
\text { M BL, } \\
\text { Fischer FM }\end{array}$ & 2004 & Cad Psicol Soc T rab. \\
\hline $\begin{array}{l}\text { A spectos ergonômicos na organização do traba- } \\
\text { Iho da equipe de enfer magem de uma U nidade de } \\
\text { T erapia I Intensiva }{ }^{(12)}\end{array}$ & Costa CC & 2005 & $\begin{array}{l}\text { U niversidade F ederal do } \\
\text { Rio G rande do Sul } \\
\text { [ dissertação] }\end{array}$ \\
\hline $\begin{array}{l}\text { Exposição dos trabalhadores de enfermagem às } \\
\text { cargas químicas em um hospital público univer- } \\
\text { sitário da cidade de São Paulo(13) }\end{array}$ & $\begin{array}{l}\text { Costa TF, } \\
\text { Felli VEA }\end{array}$ & 2005 & $\begin{array}{l}\text { Rev Latino-Am } \\
\text { Enfermagem }\end{array}$ \\
\hline $\begin{array}{l}\text { Trabalho no hospital: ritmos frenéticos, rotinas } \\
\text { entediantes }\end{array}$ & Osorio C & 2006 & Cad Psicol Soc T rab. \\
\hline
\end{tabular}


Continuação.

\begin{tabular}{|c|c|c|c|}
\hline T ítulo & Autores & Ano & Origem Publicação \\
\hline $\begin{array}{l}\text { Desgaste emocional: depoimentos de enfermei- } \\
\text { ros que atuam no ambiente hospitalar }{ }^{(15)}\end{array}$ & $\begin{array}{l}\text { Fonseca AM, } \\
\text { Soares E }\end{array}$ & 2006 & Rev RENE. \\
\hline $\begin{array}{l}\text { F atores associados à carga de trabal ho de enfer- } \\
\text { magem em U nidade de Terapia I ntensiva adulto } \\
\text { no primeiro dia de internação(16) }\end{array}$ & G onçalves LA & 2006 & $\begin{array}{l}\text { Universidade de São Paulo } \\
\text { [ dissertação] }\end{array}$ \\
\hline $\begin{array}{l}\text { E studo sobre a problemática de saúde dos traba- } \\
\text { Ihadores de enfer magem: per spectivas para vigi- } \\
\text { lância à Saúde }{ }^{(17)}\end{array}$ & Cruz ESB & 2006 & $\begin{array}{l}\text { Universidade de São Paulo } \\
\text { [ disser tação] }\end{array}$ \\
\hline $\begin{array}{l}\text { A cidentes e cargas de trabal ho dos trabalhadores } \\
\text { de enfermagem de um hospital universitário do } \\
\text { norte do Paraná(18) }\end{array}$ & Secco IAO & 2006 & $\begin{array}{l}\text { Universidade de São Paulo } \\
\text { [ tese] }\end{array}$ \\
\hline $\begin{array}{l}\text { O trabal ho de enfer magem psiquiátrica e os pro- } \\
\text { blemas de saúde dos trabal hadores }{ }^{(19)}\end{array}$ & $\begin{array}{l}\text { Carvalho M B, } \\
\text { Felli VEA }\end{array}$ & 2006 & $\begin{array}{l}\text { Rev L atino-Am } \\
\text { Enfermagem }\end{array}$ \\
\hline $\begin{array}{l}\text { Perfil dos profissionais de enfermagem com for- } \\
\text { mação em nível de ensino médio e atuantes nas } \\
\text { unidades hospitalares do município de Cacoal - } \\
\text { Rondônia(20) }\end{array}$ & Lima AAC & 2006 & $\begin{array}{l}\text { U niversidade de Brasília } \\
\text { [ dissertação] }\end{array}$ \\
\hline $\begin{array}{l}\text { A cidentes de trabal ho com trabalhadores de en- } \\
\text { fermagem }\end{array}$ & $\begin{array}{l}\text { Ribeiro EJG, } \\
\text { Shimizu HE }\end{array}$ & 2007 & Rev Bras Enferm. \\
\hline $\begin{array}{l}\text { D imensionamento de pessoal de enfermagem na } \\
\text { unidade semi-intensiva de um hospital universi- } \\
\text { tário de Curitiba(22) }\end{array}$ & $\begin{array}{c}\text { Wolff L, } \\
\text { M azur C, } \\
\text { W iezbicki C, } \\
\text { Barros C, } \\
\text { Quadros V }\end{array}$ & 2007 & Cogitare E nferm. \\
\hline $\begin{array}{l}\text { A relação trabalho-saúde dos enfer meiros do Pro- } \\
\text { grama Saúde da F amília da região de Vila Pru- } \\
\text { dente-Sapopemba: um estudo de caso(23) }\end{array}$ & Santos VC & 2007 & $\begin{array}{l}\text { U niversidade de São Paulo } \\
\text { [ dissertação] }\end{array}$ \\
\hline $\begin{array}{l}0 \text { trabalho em urgência e emergência e a relação } \\
\text { com a saúde das profissionais de enfermagem }\end{array}$ & $\begin{array}{l}\text { Dal Pai } D, \\
\text { Lautert L }\end{array}$ & 2008 & $\begin{array}{l}\text { Rev L atino-Am } \\
\text { Enfermagem }\end{array}$ \\
\hline $\begin{array}{l}\text { I mpact of the } 2004 \mathrm{G} \text { eneral M edical Services contract } \\
\text { on practice nurses: a qualitative study }{ }^{(25)}\end{array}$ & $\begin{array}{c}\text { M cG regor W, } \\
\text { Jabareen H, } \\
\text { O'D onnell CA, } \\
\text { M ercer SW, } \\
\text { Watt GCM }\end{array}$ & 2008 & $\mathrm{Br} J \mathrm{G}$ en Pract. \\
\hline $\begin{array}{l}\text { Coping e adoecimento cardíaco em um trabal ha- } \\
\text { dor da saúde }{ }^{(26)}\end{array}$ & $\begin{array}{l}\text { Santos K, } \\
\text { M artendal L }\end{array}$ & 2008 & Psicol A rgum \\
\hline $\begin{array}{l}\text { Avaliação dos fatores de sofrimento e prazer no } \\
\text { trabal ho em um centro de atenção psicosso- } \\
\text { cial(27) }\end{array}$ & Glanzner $\mathrm{CH}$ & 2008 & $\begin{array}{l}\text { U niver sidade Federal do } \\
\text { Rio Grande do Sul } \\
\text { [ dissertação] }\end{array}$ \\
\hline
\end{tabular}


Continuação.

\begin{tabular}{|c|c|c|c|}
\hline T ítulo & Autores & Ano & Origem Publicação \\
\hline $\begin{array}{l}\text { E studo comparativo da carga de trabal ho de en- } \\
\text { fermagem em U nidade de Terapia Intensiva ge- } \\
\text { ral e especializada segundo o N ursing Activities } \\
\text { Score }\end{array}$ & Queijo AF & 2008 & $\begin{array}{l}\text { Univer sidade de São Paulo } \\
\text { [ tese] }\end{array}$ \\
\hline $\begin{array}{l}\text { Lesões osteomusculares entre trabalhadores de } \\
\text { um hospital mexicano e a ocorrência de absen- } \\
\text { teísmo(29) }\end{array}$ & Díaz M CM & 2008 & $\begin{array}{l}\text { U niver sidade de São Paulo } \\
\text { [ tese] }\end{array}$ \\
\hline $\begin{array}{l}\text { Qualidade de vida dos enfermeiros das equipes } \\
\text { de Saúde da F amília( }{ }^{(30)}\end{array}$ & Fernandes JS & 2009 & $\begin{array}{l}\text { Universidade F ederal do } \\
\text { Triângulo M ineiro } \\
\text { [ dissertação] }\end{array}$ \\
\hline $\begin{array}{l}\text { A qualidade de vida no trabalho: dimensões ere- } \\
\text { percussões na saúde do trabal hador de enferma- } \\
\text { gem de terapia intensiva }{ }^{(31)}\end{array}$ & Ramos EL & 2009 & $\begin{array}{l}\text { U niver sidade do Estado do } \\
\text { Rio de Janeiro } \\
\text { [ dissertação] }\end{array}$ \\
\hline $\begin{array}{l}\text { Estudo de aspectos profissionais e psicossociais } \\
\text { no trabalho e a depressão em enfermeiros atuan- } \\
\text { tes em ambiente hospital ar }{ }^{(32)}\end{array}$ & M anetti M L & 2009 & $\begin{array}{l}\text { U niversidade de São Paulo } \\
\text { [ tese] }\end{array}$ \\
\hline $\begin{array}{l}\text { Tempo médio de cuidado ao paciente de alta de- } \\
\text { pendência de enfermagem segundo o N ursing } \\
\text { Activities } S \text { core } \text { (33) }^{(33)}\end{array}$ & Tsukamoto R & 2010 & $\begin{array}{c}\text { U niver sidade de São Paulo } \\
\text { [ dissertação] }\end{array}$ \\
\hline
\end{tabular}

Q uadro 1 - Distribuição dos estudos segundo o título, autor(es), ano e origem. F lorianópolis, SC, 2010.

Fonte: Banco Digital de T eses e Biblioteca Virtual de Saúde, jan. 2000/ ago. 2010.

A partir do Quadro 1 é possível evidenciar que periódicos da área de enfermagem foram os que mais divulgaram trabalhos sobre 0 tema. A partir de 2006 houve um aumento do número de publicações nessa temática, o que pode estar relacionado com a publicação da Resolução 293/04 do Conselho Federal de Enfermagem sobre Dimensionamento de Pessoal de Enfermagem(34), já que alguns estudos a partir dessa data trazem tal perspectiva. Outro aspecto que pode ter influenciado as produções foi a estruturação, a partir de 2002, da Rede Nacional de Atenção I ntegral à Saúde do T rabal hador no Sistema Ú nico de Saúde (SU S), por meio da Portaria 1679(35), quando já eram encontrados vários estudos sobre a saúde dos trabal hadores. D estaca-se que outros estudos podem ter sido realizados, porém não foram capturados em função das expressões utilizadas.

E $m$ relação aos instrumentos utilizados para coleta de dados, treze trabalhos $(48,14 \%)$ utilizaram dois tipos de instrumento, dez pesquisas utilizaram apenas um $(37,03 \%)$ e quatro $(14,48 \%)$ utilizaram a triangulação.
Os instrumentos para coleta de dados foram utilizados com finalidades distintas. Foram eles: $\mathrm{N}$ ursing Activities Score (NAS) $)^{(16,22,28,33)}$, Simplified A cute P hysiology Score (SAPS II) $)^{(16,28)}$ e o L ogistic Organ D isfuncion System (LODS)(28).

Esses instrumentos estão voltados ao levantamento da carga de trabal ho para subsidiar cálculos de necessidade de força de trabal ho para a prestação de cuidados, ou seja, apontam a carga de trabalho como volume/ quantidade de trabalho, mas não associam as cargas e a influência que estas podem ter uma sobre a outra. U m dos autores relaciona que a equipe de enfermagem é submetida à sobrecarga de trabal ho constante, que se relaciona à variabilidade, simultaneidade das tarefas e responsabilidade nos cuidados prestados ${ }^{(36)}$. Contudo, 0 autor ainda relata que a realização das tarefas depende da colaboração entre colegas, que influi diretamente no relacionamento intraequipe ${ }^{(36)}$. Com esse ol har, amplia-se o leque de interações das cargas de trabal ho para além das condições ambientais, materiais e de processo de trabalho, incluindo-se o relacionamento interpessoal na equipe e as formas de organização do trabalho. 
Os sujeitos das pesquisas foram os enfermeiros em sete trabal hos $(25,92 \%)$, a equipe de enfermagem em doze $(44,44 \%)$ e a equipe multiprofissional de saúde, que apareceu em dois estudos $(7,40 \%)$. Em seis trabalhos $(22,22 \%)$ os pacientes foram os sujeitos do estudo, entretanto, em todos eles 0 objetivo foi mensurar a carga de trabalho para enfermagem oriunda dos cuidados prestados a esses sujeitos, ou ainda as condições de trabalho e o tempo de permanência junto ao paciente.

Como campo de coleta de dados, 22 pesquisas $(81,48 \%)$ foram realizadas no ambiente hospitalar, sendo que, dentre estas, cinco $(22,72 \%)$ foram em U nidades de T ratamento I ntensivo (UTI). Outros campos de investigação foram: Estratégia de Saúde da F amília (E SF ), com três estudos (11\%); um estudo (3,70\%) no Centro de A tenção Psicossocial (CAPS); uma investigação $(3,70 \%)$ não especificou o campo.

Há o reconhecimento do ambiente hospitalar como insalubre, penoso e perigoso para os profissionais, sendo um local privilegiado para 0 adoecimento, com riscos de acidentes e doenças de ordem física(37). Além disso, ressalta-se o crescente risco de sofrimento psíquico, devido à alta pressão social e psicológica a que estão submetidos os profissionais tanto na esfera do trabal ho quanto fora dela. As difíceis condições de trabalho e de vida podem estar relacionadas a ocorrências de transtornos mentais, como ansiedade e depressão.

Ressalta-se que o tema cargas de trabal ho de enfermagem tem sido mundialmente discutido, com vistas a sua implicação na qualidade da assistência prestada aos pacientes, na qualidade de vida dos profissionais de saúde e nos custos hospital ares ${ }^{(28)}$. Além disso, o tema é particularmente importante nas UTIS, devido ao impacto das novas tecnologias no cuidado, às mudanças no perfil dos pacientes graves e às necessidades de mão de obra especializada com aumento dos custos nesse setor.

N esse contexto, apesar dos termos carga de trabalho e cargas de trabalho apresentarem expressões semelhantes e mesclarem-se na prática, traduzem abordagens diferentes. As condições de trabalho ${ }^{(38)}$ estão relacionadas às cargas de trabaIho (físicas, químicas, biológicas, mecânicas, fisiológicas e psíquicas) a que o profissional está submetido. Sob outro enfoque, o termo carga de trabal ho é visto com relação ao dimensionamento de pessoal, enquanto quantidade de trabalho.
0 que se observa, portanto, é uma diversidade de entendimentos sobre cargas de trabalho, ou seja, em alguns estudos a carga de trabalho é entendida como algo mensurável, principalmente nos estudos que consideram esse item como um dos requisitos para o dimensionamento de pessoal, utilizando instrumentos próprios para a sua mensuração, como, por exemplo, o NAS. Outros estudos entendem as cargas de trabalho na perspectiva da saúde do trabalhador e das condições de trabal ho( ${ }^{(38)}$.

N esse sentido, identificou-se nesta revisão integrativa que parte dos estudos aponta a construção e/ ou adaptação de instrumentos que aumentam a carga de trabal ho principalmente em unidades críticas, oferecendo-os como forma de classificar os pacientes atendidos e a dependência que estes apresentam em relação à equipe de enfermagem, além do tempo que a equipe emprega assistindo o doente $e^{(7,28,39)}$.

Ainda percebeu-se nos estudos o interesse dos pesquisadores em relacionar as cargas de trabalho e os acidentes de trabalho, pesquisar os recursos dos trabalhadores para fazer frente, principalmente, à carga psíquica, encontrada como causadora dos desgastes físicos e emocionais da equipe de enfermagem e de saúde.

$E m$ relação às condições de trabal ho evidenciou-se a ênfase nas condições ergonômicas do ambiente laboral, com enfoque nas lesões osteomusculares e no absenteísmo por decorrência destas.

Quando analisado o referencial teórico/conceitual utilizado nos estudos, apenas seis estudos $(22,22 \%)$ o definiram. Esses estudos consideram as cargas de trabal ho como el ementos do processo de trabal ho que interagem entre si e com o corpo do trabalhador, desencadeando alterações nos processos biopsíquicos, que se manifestam como desgastes físicos e psíquicos potenciais ou efetivamente apresentados, os quais devem, portanto, ser analisados no contexto do processo de trabal ho(5).

Entendem-se as cargas de trabalho como os el ementos que sintetizam a mediação entre 0 trabalho e 0 desgaste do trabalhador, as quais não atuam isoladamente, mas em combinação com outras cargas que deter minam a condição na qual 0 trabalhador enfrenta a lógica global do processo de trabalho(5). No contexto dessas considerações se observa que a carga de trabalho enquanto "sobrecarga de trabal ho" interfere diretamente no processo de desgaste laboral, tendo relação com as condições de trabalho. 
Buscando-se analisar os resultados das produções sobre as cargas de trabal ho e as condições de trabal ho da equipe de enfer magem, evidenciouse, em parte dos estudos, as cargas de trabalho como responsáveis pelo desgaste emocional dos profissionais.

Estudiosos observam que para melhor compreender as cargas de trabal ho é necessário classificá-las, podendo ser agrupadas em cargas físicas, químicas, biológicas/ orgânicas, mecânicas, fisiológicas e psíquicas(5,39), as quais interferem nas condições de trabalho e na saúde dos profissionais.

As cargas físicas são derivadas principalmente das exigências técnicas para a transformação do objeto de trabalho e caracterizam um determinado ambiente de trabalho, com o qual o trabal hador interage cotidianamente. As cargas químicas derivam principalmente do objeto de trabal ho e dos meios auxiliares envolvidos em sua transformação, caracterizando 0 ambiente de trabalho e sua interação cotidiana com o trabalhador. Ainda são derivadas do objeto de trabal ho e das condições de higiene ambiental as cargas orgânicas, que incluem qual quer organismo animal ou vegetal que possa determinar danos à saúde do trabalhador ${ }^{(39)}$.

Já as cargas mecânicas são derivadas principal mente da tecnologia, devido a sua operação ou manutenção, aos materiais disponíveis ou ao próprio objeto de trabalho. Essas cargas, no momento em que o trabal hador interage com elas, representam exigências a sua integridade biopsicossocial.

Em relação às cargas fisiológicas e psíquicas, defini-se que as primeiras são oriundas das diversas maneiras de se realizar as atividades e estão constituídas por elementos como esforço físico ou visual, deslocamentos e movimentos exigidos pelas tarefas, espaço de trabalho disponível, posições assumidas em sua execução, horas extras ou intensificação do trabalho, jornadas prolongadas e turnos noturnos e rotativos ${ }^{(39)}$.

As cargas psíquicas constituem-se de elementos que acima de tudo são fontes de estresse. N esse sentido, pode-se considerar que estas se relacionam com todos os elementos do processo de trabaIho e, portanto, com as demais cargas de trabal ho. $\mathrm{N}$ o entanto, em termos mais específicos, a principal fonte pode ser localizada na forma e dinâmica da organização e divisão do trabalho. Não podem ser conceituadas senão em relação ao corpo do trabalhador; sua materialidade está nos pro- cessos corporais transformados, ou seja, na corporeidade humana ${ }^{(5)}$.

$\mathrm{N}$ a realidade laboral da equipe de enfermagem, enfaticamente no ambiente hospitalar, há sobrecarga de trabal ho constante, a qual depende da variabilidade e simultaneidade das tarefas e das responsabilidades nos cuidados, além das condições de trabalho ${ }^{(36,37)}$.

N esse sentido, o trabalho hospitalar apresenta aspectos muito específicos, como a excessiva carga de trabal ho, o contato direto com situações limite, o elevado nível de tensão e os altos riscos para si e para os outros ${ }^{(40)}$. A existência de regime de turnos e plantões permite a ocorrência de duplos empregos e longas jornadas de trabalho, especialmente quando os salários são insuficientes para a manutenção de uma vida digna.

Como consequências da sobrecarga/ excesso de trabalho, os estudos selecionados identificaram principalmente: frequentes acidentes com material perfurocortante ou com fluídos e secreções corporais; problemas de saúde, como contusões, hipertensão arterial, alergias, epigastralgias, problemas musculoesqueléticos, adoecimento/ sofrimento mental, entre outros. A pontaram, ainda, que essas são al gumas das causas do afastamento do trabalho por parte dos profissionais de enfermagem. Entretanto, grande parte dos trabalhadores não percebe os riscos ocupacionais a que estão expostos.

T rabalhos de revisão bibliográfica recentes apontam para o crescente adoecimento dos trabaIhadores de enfermagem, resultado das inadequadas condições de trabalho. E sses estudos enfatizam a necessidade de aprofundar os métodos de investigação desses distúrbios relacionados ao trabalho da enfermagem, bem como a grande importância de repensar a organização do trabal ho desses profissionais ${ }^{(41)}$.

0 aumento das cargas, somado às más condições de trabalho, aponta para uma diminuição da capacidade de trabalho dos profissionais da área. Os turnos de trabalho também apresentam diferentes cargas. A parentemente, a atividade noturna pode apresentar uma redução de trabal ho, entretanto o quantitativo de pessoal também é reduzido, elevando assim as cargas de trabalho, somando-se às cargas fisiológicas pelo horário noturno. Já a jornada diurna apresenta, dentre as cargas de trabalho, a mecânica como mais evidenciada, pela característica dos cuidados com manipulação físi- 
ca, que acontecem majoritariamente nesse período. É observada assim a importância de adequar 0 número de pessoas em cada turno e setor às demandas do hospital e dos pacientes, com o objetivo de superar as dificuldades e promover melhores condições de trabal ho $0^{(16,17,36,37)}$.

Entre os achados observou-se o registro, pelos autores, da característica capitalista da sociedade atual como elemento influenciador no trabaIho de enfermagem. Dentre as influências, destacou-se 0 aumento da jor nada de trabal ho sem proporcional aumento da remuneração, além do aumento do ritmo de trabal ho sem aumento do quantitativo de trabalhadores ${ }^{(14,36)}$.

Observou-se também que as pesquisas enfatizaram 0 aumento do volume de trabal ho e a necessidade de domínio de tecnologias como aspectos que reduzem o tempo da equipe de enfermagem disponível para o cuidado dos pacientes ${ }^{(16,17)}$. Constatou-se que o cuidado direto com os pacientes tem sido identificado como fonte de prazer e gratificação, capaz de minimizar as perdas, inclusive as financeiras ${ }^{(37)}$. Com isso percebe-se que o prazer do trabal ho está no cuidado do paciente, na sensação do trabal ho cumprido, enquanto o desprazer, em geral, relaciona-se com a organização e com as condições de trabal ho da enfermagem.

Outro ponto discutido foi a distância entre 0 trabal ho prescrito e o realizado, bem como a contradição entre 0 ideal de trabal ho de equipe em prol do paciente e o trabal ho real, fragmentado e real izado em ambiente com pouca cooperação entre grupos e categorias profissionais. As pesquisas mostram que os trabalhadores de enfermagem são responsáveis por tarefas árduas: manobras de reanimação cardiopulmonar, curativos, aspiração de secreções, cuidados de higiene e conforto, manipulação de mobiliário e equipamentos inadequados, danificados e obsoletos, movimentos repetitivos, trabalho em espaços reduzidos, sob iluminação inadequada ${ }^{(14,17)}$. Esses aspectos sinalizam o risco de aumento demasiado das cargas de trabal ho entre esses profissionais e a necessidade de medidas que amenizem/ eliminem essas cargas, como investimentos na mel horia das condições de trabal ho desses indivíduos.

Parte dos estudos sugere a utilização de base científica para subsidiar a prática gerencial do en-

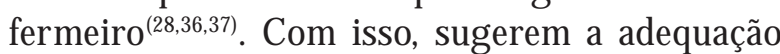
entre as necessidades de cuidado dos usuários e quantitativo de pessoal de enfermagem por turno e setor, com o objetivo de superar as dificuldades das tarefas e promover melhores condições de trabalho.

Para recuperação do desgaste da carga de trabalho é importante o desenvolvimento de estratégias de prevenção relacionadas ao ambiente da jor nada (descanso, refeições), busca de melhores condições de trabal ho, aumento da remuneração desses profissionais, maiores benefícios e investimentos na educação continuada $a^{(17,28,41)}$.

Os estudos apontam ainda a necessidade de aprofundamento das reflexões acerca da organização do trabalho em seus aspectos amplos, que envolvem desde as condições de trabalho, a divisão, bem como as relações, no sentido de encontrarem-se estratégias para minimizar o desgaste do trabal hador neste processo.

\section{CONCLUSÕES}

E ntre os estudiosos do campo da saúde do trabalhador, destacam-se nas produções as formulações teóricas de L aurell e N oriega, as quais tem se constituído no principal referencial(5) utilizado para estudar cargas de trabal ho e condições de trabaIho na enfermagem.

Os estudos identificam as cargas de trabal ho como responsáveis pelo desgaste emocional dos profissionais de saúde e enfer magem, e como consequência da sobrecarga/ excesso de cargas de trabal ho identificaram a ocorrência de acidentes e problemas de saúde. Com isso, sugerem que a prática gerencial do(a) enfermeiro(a) deve sustentar-se em bases científicas para melhor fundamentar a defesa de quantitativo adequado de pessoal, educação continuada, formulação de estratégias de promoção de melhores condições de trabal ho e de prevenção do adoecimento profissional. Propõem essas estratégias para mel horar as condições de trabal ho da enfer magem e amenizar/ eliminar as cargas de trabal ho desses profissionais.

As expressões "carga de trabalho" e "cargas de trabal ho" são citadas ora fazendo referência às condições de trabalho, ora relacionando-se ao dimensionamento de pessoal de enfermagem, o que aponta os temas como convergentes e complementares dentro do contexto das condições de trabaIho da enfermagem.

Desse modo, tem-se como desafio a realização de pesquisas que revel em com mais precisão a relação entre as cargas de trabal ho e as condições 
de trabalho da equipe de enfermagem, bem como estudos que auxiliem a amenizar/ eliminar as cargas e promover melhores condições laborais.

\section{REFERÊNCIAS}

1 Pires D. Reestruturação produtiva e trabalho em saúde no Brasil. 2ª ed. São Paulo: A nnaBlume/ CNT SS; 2008.

2 Capella BB. U ma abordagem sócio-humanista para um "modo de fazer" o trabalho de enfermagem. Pelotas: Universitária/ U F PEL; 1996.

3 M edeiros SM , Ribeiro LM , Fernandes SM BA, Veras VSD. Condições de trabal ho e enfermagem: a transversalidade do sofrimento no cotidiano. Rev E letrônica E nferm [ I nter net] . 2006 [ citado 2011 jan 23] ; 8(2):233-40. D isponível em: http:/ / www.fen.ufg.br/ revista/ revista8_2/ v8n2a08.htm.

4 G elbcke FL, T avares CM A, M atos E, Fertonani H P, Silvestrim NAS, Shiroma L M B, et al. T rabalho, saúde, cidadania e enfer magem: produção do conhecimento do G rupo Práxis. T exto Contexto Enferm. 2008;17 (4):723-33.

5 Laurell AC, Noriega M. 0 processo de produção e saúde: trabal ho e desgaste operário. São Paulo: H ucitec; 1989.

$6 \mathrm{G}$ anong $\mathrm{LH}$. Integ rative review of nursing research. Res N urs H ealth. 1987;10(1):1-11.

7 Perroca M G. Instrumento de classificação de pacientes de Perroca: validação clínica [ tese] . São Paulo: U niversidade de São Paulo; 2000.

8 Santos PR. Estudo do processo de trabal ho da enfermagem em hemodinâmica: desgastes, cargas de trabal ho e fatores de riscos à saúde do trabal hador [ dissertação] . Rio de Janeiro: Escola $N$ acional de Saúde Pública, F undação O svaldo Cruz; 2001.

9 Nóbrega M FB, Jorge M SB, Valdés M T M, Silva LM S. Formação do enfermeiro para detecção precoce de desvios psicomotores em lactentes - Fortaleza, Estado do Ceará, Brasil. A cta Sci H ealth Sci. 2003;25(2):183-90.

10 Perroca M G, G aidzinski RR. A nálise da validade de constructo do instrumento de classificação de pacientes proposto por Perroca. Rev Latino-Am Enfermagem. 2004;12(1):83-91.

11 Gonçalves M BL, Fischer F M . Condições de trabaIho de auxiliares de enfermagem de um instituto de ortopedia e traumatologia de um hospital público de
São Paulo. Cad Psicol Soc T rab [ I nternet] . 2004 [ citado 2011 mar 24];7:51-6. Disponível em: http:// www.revistasusp.sibi.usp.br/ pdf/ cpst/ v7/ v7a06.pdf.

12 Costa CC. A spectos ergonômicos na organização do trabal ho da equipe de enfermagem de uma U nidade de Terapia Intensiva [ dissertação] . Rio Grande do Sul: E scola de Engenharia, U niversidade F ederal do Rio Grande do Sul; 2005.

13 Costa TF, Felli VEA. Exposição dos trabalhadores de enfermagem às cargas químicas em um hospital público universitário da cidade de São Paulo. Rev Latino-A m E nfermagem. 2005;13(4):501-8.

14 Osorio C. T rabalho no hospital: ritmos frenéticos, rotinas entediantes. Cad Psicol Soc T rab. 2006;9(1): 15-32.

15 Fonseca AM , Soares E. D esgaste emocional: depoimentos de enfer meiros que atuam no ambiente hospitalar. Rev REN E . 2006;7(1):91-7.

$16 \mathrm{G}$ onçalves $\mathrm{LA}$. F atores associados à carga de trabaIho de enfermagem em UTI adulto no primeiro dia de inter nação [ dissertação] . São Paulo: U niversidade de São Paulo; 2006.

17 Cruz E BS. E studo sobre a problemática de saúde dos trabal hadores de enfermagem: per spectivas para $\mathrm{Vi}$ gilância à Saúde [ dissertação] . São Paulo: U niversidade de São Paulo; 2006.

18 Secco IAO. A cidentes e cargas de trabalho dos trabalhadores de enfermagem de um hospital universitário do norte do Paraná [ tese] . Ribeirão Preto: E scola de E nfermagem de R ibeirão P reto, U niversidade de São Paulo; 2006.

19 Carvalho M B, Felli VE A . 0 trabal ho de enfermagem psiquiátrica e os problemas de saúde dos trabal hadores. Rev Latino-Am Enfermagem. 2006;14(1):61-9.

20 Lima AAC. Perfil dos profissionais de enfermagem com formação em nível de ensino médio e atuantes nas unidades hospitalares do município de Cacoal Rondônia [ dissertação] . Brasília (DF): U niversidade de Brasília; 2006.

21 Ribeiro EJG, Shimizu HE . A cidentes de trabal ho com trabalhadores de enfermagem. Rev Bras Enferm. 2007;60(5):535-40.

22 Wolff LDG, M azur CS, W iezbicki C, Barros CB, Quadros VAS. Dimensionamento de pessoal de enfer magem na unidade semi-intensiva de um hospital universitário de Curitiba. Cogitare E nferm. 2007;12 (2):171-82. 
23 Santos VC. A relação trabalho-saúde dos enfermeiros do Programa Saúde da F amília da região de Vila Prudente-Sapopemba: um estudo de caso [ dissertação] . São Paulo: U niversidade de São Paulo; 2007.

24 D al Pai D, L autert L. 0 trabalho em urgência e emergência e a relação com a saúde das profissionais de enfermagem. Rev L atino-A m E nfer magem. 2008;16 (3):439-44.

25 M cG regor W, Jabareen H, O'D onnell CA, M ercer SW, W att G CM . I mpact of the $2004 \mathrm{G}$ eneral M edical Services contract on practice nurses: a qualitative study. Br J Gen Pract. 2008;711-9.

26 Santos K, M artendal L. Coping e adoecimento cardíaco em um trabalhador da saúde. Psicol Argum. 2008;26(55):281-92.

27 G lanzner CH. Avaliação dos fatores de sofrimento e prazer no trabalho em um centro de atenção psicossocial [ dissertação] . Rio G rande do Sul: U niversidade Federal do Rio G rande do Sul; 2008.

28 Queijo A F. E studo comparativo da carga de trabal ho de enfermagem em UTI geral e especializada segundo o Nursing Activities Score (NAS) [ tese]. São Paulo: U niver sidade de São Paulo; 2008.

29 Díaz M CM. Lesões osteomusculares entre trabaIhadores de um hospital mexicano e a ocorrência de absenteísmo [ tese] . Ribeirão Preto: E scola de E nfermagem de Ribeirão Preto, U niversidade de São Paulo; 2008.

30 Fernandes JS. Qualidade de vida dos enfer meiros das equipes de Saúde da Família [ disser tação] . U beraba: U niversidade Federal do T riângulo M ineiro; 2009.

31 Ramos E L. A qualidade de vida no trabalho: dimensões e repercussões na saúde do trabalhador de enfermagem de terapia intensiva [ disser tação] . Rio de Janeiro: U niversidade do Estado do Rio de Janeiro; 2009.

32 M anetti M L. Estudo de aspectos profissionais e psicossociais no trabal ho e a depressão em enfer meiros atuantes em ambiente hospitalar [ tese]. R ibeirão Preto: E scola de Enfermagem de Ribeirão Preto, U niversidade de São Paulo; 2009.

\section{Endereço da autora / Dirección del autor / Author's address:}

Roseli Schmoeller

Rod. A maro A ntônio Vieira, 2008, bl. 3, ap. 201, Itacorubi

88034-101, F lorianópolis, SC

E-mail: roseli@hu.ufsc.br
33 T sukamoto R. T empo médio de cuidado ao paciente de alta dependência de enfermagem segundo 0 N ursing A ctivities Score [ dissertação]. São Paulo: U niversidade de São Paulo; 2010.

34 Consel ho F ederal deE nfermagem. Resolução $n=293$, de 21 de setembro de 2004: fixa e estabel ece parâmetros para o dimensionamento do quadro de profissionais de enfer magem nas U nidades A ssistenciais das I nstituições de Saúdee Assemelhados [ I nternet] . Rio de Janeiro; 2004 [ citado 2011 mar 10] . D isponível em: http:/ / site.portal cofen.gov.br/ node/ 4329.

35 M inistério da Saúde (BR), Secretaria de A tenção à Saúde, D epartamento de A ções Programáticas E stratégicas. L egislação em saúde: caderno de legislação em saúde do trabalhador. 2a ed. Brasília (DF); 2005.

36 Antunes AV, Costa M N. Dimensionamento de pessoal de enfermagem em um hospital universitário. Rev L atino-A m E nfermagem. 2003;11(6):21-32.

37 E lias M A, N avarro VL . A relação entre o trabal ho, a saúde e as condições de vida: negatividade e positividade no trabal ho das profissionais de enfermagem de um hospital-escola. Rev L atino-A m E nfermagem. 2006;14(4):517-25.

$38 \mathrm{~L}$ aurell AC. A saúde-doença como processo social. In: N unes ED, organizadores. M edicina social: aspectos históricos e teóricos. São Paulo: G lobal; 1983. p. 133-58.

$39 \mathrm{~F}$ acchini LA . I sto é trabal ho de gente? Vida, doença e trabalho no Brasil. São Paulo: Vozes; 1993.

40 Pitta A. H ospital, dor e morte como ofício. 2ª ed. São Paulo: H ucitec; 1991.

41 M agnago T SBS, L isboa M T L, G riep R H. T rabalho da enfer magem e distúrbio musculoesquelético: revisão das pesquisas sobre o tema. Esc Anna Nery. 2008;12(3):560-5.

42 T rindade $L L$, G onzales R M B, Beck CL C, L autert L. Cargas de trabalho entre os agentes comunitários de saúde. Rev G aúcha E nfem. 2007;28(4):473-9.

Recebido em: 01/ 03/ 2011

A provado em: 01/ 06/ 2011 